\title{
NARRATIVAS EM CULTURA E ARTE CONTEMPORÂNEA: EXPERIÊNCIA DIDÁTICA VIA MITEA NA FORMAÇÃO DE PROFESSORES EM ARTES VISUAIS
}

\author{
Flávia Maria de Brito Pedrosa Vasconcelos \\ Universidade Federal do Vale do São Francisco
}

\section{Resumo}

Este artigo analisa a construção e o desenvolvimento das aulas da disciplina "Cultura e Arte Contemporânea", ministrada a professores/alunos das redes municipal e estadual de ensino, na cidade de Juazeiro/BA, que cursam a Licenciatura em Artes Visuais do Programa de Formação Inicial de Professores - Plataforma Freire. Utilizando-se de uma perspectiva dialética no ensino de Arte e por meio da proposta Multi, Inter e Trans do Ensino de Arte - MITEA, realizei inferências e discussões sobre temáticas específicas que tratam de Cultura e Arte na contemporaneidade. Trato dos discursos desenvolvidos em formato de narrativas, percebendo a eficiência deste instrumento investigativo como sintetizador de experiências didáticas. Interpreto as discussões realizadas, permeadas por discursos entre se tornar artista, pesquisador e professor de Artes Visuais. Reflito, ao fina,l acerca da importância de uma formação em artista/professor/pesquisador para os cursos de Licenciatura em Artes Visuais.

Palavras-chave: narrativas, didática, formação do professor de Artes Visuais.

\section{Abstract}

This article observe the development of "Contemporary Art and Culture" classes, giver to teacher/students of Juazeiro/BA, who study a degree in Visual Arts Teacher Graduation Program - Plataforma Freire. Using a dialetical perspective in the teaching of Art and through the Multi, Inter and Trans Teaching Art Proposal - MITEA, I made inferences and discussions on specific issues dealing with Culture and Art in contemporary society. I develop the discourse in narratives view, understanding the efficiency of this instrument as a investigative students experiments synthesizer. Interpret the discussions, permeated by discourses between becoming an artist, researcher and professor of Visual Arts. At the end, I reflect about the importance of graduation as artist/teacher/ 
researcher for Visual Arts Teacher's graduations.

Keywords: narratives, didactical, Visual Arts Teacher graduation.

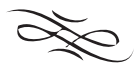

\section{Passos iniciais na mediação educativa em artes visuais}

Em fevereiro de 2011, iniciei a mediação pedagógica na disciplina Cultura e Arte Contemporânea (primeira no núcleo de formação básica) com a turma de professores/ alunos $^{1}$ do curso de Licenciatura em Artes Visuais do Programa de Formação Inicial de Professores - Programa Plataforma Freire, no campus Juazeiro da Universidade Estadual da Bahia (UNEB).

O Programa Plataforma Freire é mantido pela Coordenação de Aperfeiçoamento de Pessoal de Nível Superior (CAPES) e tem como objetivo oferecer cursos de graduação gratuitos e de qualidade para professores da rede estadual e municipal, que, de acordo com a Lei de Diretrizes e Bases da Educação Nacional (LDBEN) 9394/1996, estão atuando nas escolas sem formação adequada à/s disciplina/s que trabalham.

Por não terem formação específica, os professores reproduzem conceitos, técnicas e metodologias que não se adequam às necessidades do processo de ensino/aprendizagem em arte, conforme é considerado pelo Parecer $n^{\circ}$ 09/2001² do Conselho Nacional de Educação (CNE):

[...] o professor, nem sempre consegue criar, planejar, realizar, gerir e avaliar situações didáticas eficazes para a aprendizagem e para o desenvolvimento dos alunos se ele não compreender, com razoável profundidade e com necessária adequação à situação escolar, os conteúdos das áreas do conhecimento que serão objeto de sua atuação didática, os contextos em que se inscrevem e as temáticas transversais ao currículo escolar. (CNE/CP 009/2001)

Sabendo que os professores/alunos lecionavam Artes nas escolas públicas e não possuíam formação na área, a organização das atividades na disciplina partiu da concepção de que o processo de ensino é uma construção didática desenvolvida por meio da mediação pedagógica em que professor e aluno analisam, questionam, refletem sobre o conhecimento.

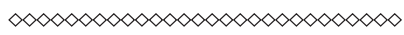

1 Considero como professores/alunos devido ao fato de que antes de entrarem no curso, além de já estarem há anos como professores efetivos em escolas municipais e/ou estaduais, possuíam formação que os habilitasse para a docência, atuando no ensino de Arte, sem a formação específica para esta disciplina.

2 O Parecer No 09/2001, trata das Diretrizes Curriculares Nacionais para a Formação de Professores da Educação Básica, em nível superior, curso de licenciatura, de graduação plena e pode ser visualizado em: <http://www.preg.ufms.br/DIAP/ESTAGIO/Parecer-CNE-092001.htm>. Acesso em: 11 fev. 2012. 
Organizei a disciplina em três unidades, de acordo com a ementa, tratando na unidade I dos conceitos em cultura e arte contemporânea, produção e patrimônio cultural, produção artística em Artes Visuais. Na unidade II, da integração social da arte e da cultura, identidade cultural e multiculturas, bem como narrativas visuais de memória e tradição. Na unidade III, sobre a economia da cultura e da arte, o mercado de Artes Visuais e as políticas públicas culturais no Brasil.

Em relação aos objetivos, procurei descrever e discutir conceitos em cultura e arte contemporânea, analisando e investigando concepções existentes nos textos e nos discursos narrados pelos professores/alunos.

O ensino/aprendizado foi sendo construído no processo, a partir da exposição, estudos dirigidos e leitura de imagens e vídeos. Inspirada nos ideais de Freire (2005), busquei na problematização o desenvolvimento de noções compartilhadas e debatidas em grupo, mediando e ressignificando a leitura de textos e imagens, as perguntas iam sendo feitas de acordo com os conhecimentos abordados.

Trato dos conceitos em narrativas, de acordo com os enunciados em Vasconcelos (2011b), ao explicitar a relação intrínseca de reflexão das teorias e práticas educativas e artísticas por meio do recurso às narrativas na formação de professores de Artes Visuais. Também me apoio, para construir os discursos, na perspectiva dialética em Vasconcellos (2009), que aborda a maneira como o professor se coloca nas aula pela forma como entende seu papel social, na construção com o aluno do conhecimento significativo para ambos.

\section{Narrativas didáticas dos professores/alunos}

Os professores/alunos que cursaram a disciplina Cultura e Arte Contemporânea, trabalhavam com a disciplina Artes, seja na rede estadual ou municipal de ensino. A escolha ou a lotação destes professores na disciplina Artes nas escolas se deu devido a fatores político/pedagógicos que envolviam, principalmente, a complementação da carga horária de outras disciplinas e não a formação adequada ara a área.

Foi observado um expressivo número de professores/alunos que não tinham contato anterior ou contínuo com a área de Arte como experiência artística, na produção e criação de objetos e ações. A maior parte não havia mantido ainda contato com obras de arte, museus, espaços expositivos, o sistema que funciona o mercado de arte, nem com as políticas públicas em cultura.

Decidi então solicitar que narrassem suas relações com a Arte, na construção da identidade pessoal, na escola como alunos e posteriormente como professores na área de Arte. O resultado foi composto de descrições de relações com a Arte, mas no que tange ao nível técnico e artesanal da criação, dentro de noções como "saber fazer", "Arte é dom" e "Arte é algo belo". 
Logo após, pedi que em algumas palavras definissem suas expectativas na disciplina Cultura e Arte Contemporânea. Muitos trataram do tema, refletindo sobre cursos de qualificação na área de Arte que haviam realizado por intermédio dos programas das secretarias de educação estadual e municipal, os quais centravam-se em compreensão e apreensão de maneira fragmentada de prática/s ou técnica/s específicas.

Definiram as necessidades ligadas a ideia de praticidade. Para a maioria dos professores/alunos, a disciplina deveria possibilitar didáticas com temas e dinâmicas já determinados para serem aplicados imediatamente nas salas de aula em que atuavam.

Com estas informações, reorganizei o material que havia preparado, de forma a além de atender suas expectativas e necessidades, questionar e problematizar "paradigmas" sobre arte e cultura contemporânea nas aulas seguintes.

\section{Processos didáticos via MITEA: temas e discussões}

Na perspectiva do ensino de arte contemporâneo, os processos didáticos são parte do aprendizado de ser professor e traduzem uma maneira de se enxergar como profissional da educação, no cotidiano das aulas.

Visualizando que todos reflexionam e constroem o aprendizado em conjunto, busquei estimular de maneiras multi, inter e trans o ensinar/aprender artes (MITEA). Esta proposta é explicitada da seguinte maneira:

A denominação de Proposta MIT do Ensino de Arte (MITEA), advém da conexão intrínseca de concepções epistemológicas já existentes no Brasil, a Abordagem Triangular e o campo de estudos da Cultura Visual, tendo referência em estudos acerca do trabalho de pesquisadores que desenvolveram o conceito MIT - entre eles, Afonso Ferreira e Ionna Stravidou e do trabalho de pesquisa desenvolvido pelo pesquisador Sérgio Coelho Borges Farias, professor da Universidade Federal da Bahia(UFBA) - que estudam a noção de Multi, Inter e Trans (MIT) possibilidades de ensinar/aprender. (VASCONCELOS, 2011, p.164).

Com foco em quatro perspectivas didáticas não-lineares: as narrativas, a produção artística, os discursos visuais (o que as imagens e as produções artísticas pretendem significar/comunicar/reproduzir) e as visualidades (imagens que estão nas mídias, nas ruas, no cotidiano) em ações que possibilitam o ensino/aprendizado que contextualiza, cria, constrói, interpreta, analisa e problematiza, a MITEA é uma concepção que se situa na pós-modernidade do ensino de arte pela sua multiplicidade de utilizações pedagógicas. Abaixo segue gráfico que explicita visualmente como foi sistematizada a MITEA3:

$\alpha<\infty<\infty<\infty<\infty<\infty<\infty<\infty<\infty<\infty<\infty<\infty<$

3 O gráfico foi desenhado no formato de elipse no intuito de remeter a acepção do olhar que é construí- 


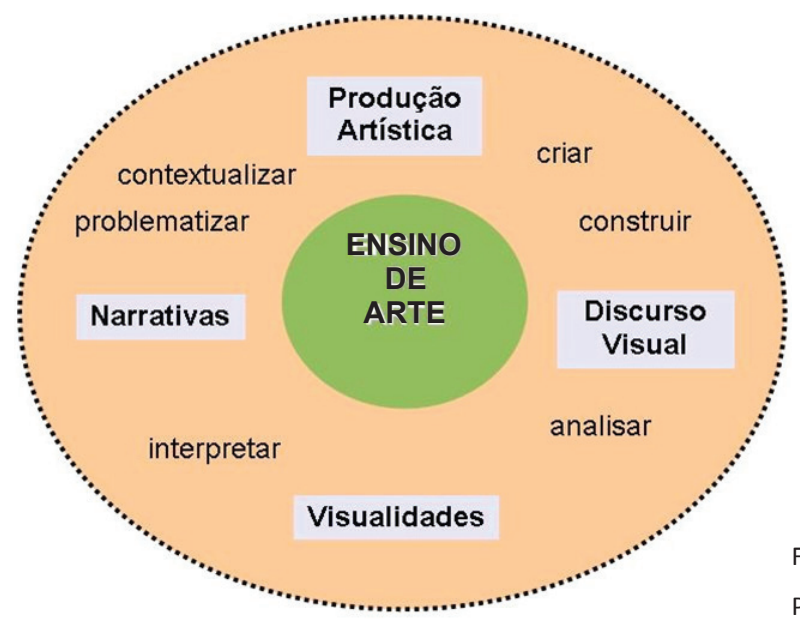

Fig. 1. Gráfico com conceitos trabalhados na Proposta MITEA

A proposta MITEA na disciplina Cultura e Arte Contemporânea guiou como concepção metodológica articulações entre os questionamentos que surgiam a cada termo, noção, imagem demonstrado, revelando um caminho em que a multiplicidade de conceitos e formulações e a interação eram parte atuantes entre os sujeitos pedagógicos.

Procurei distribuir os percursos, via MITEA, durante a disciplina, de forma que saberes construídos e adquiridos eram observados e analisados, consolidando-se em debates e na discussão com o grupo, especialmente sobre os critérios avaliativos e aplicação da avaliação.

Assim, na primeira aula, procurei discutir sobre os conceitos que envolvem a Cultura e a Arte, perguntando aos professores/alunos que noções possuíam sobre estas duas área e como poderíamos trazê-los para a noção de contemporaneidade.

Analisamos, juntos, a contemporaneidade relacionando-a com a pós-modernidade, de acordo com as enunciações de Santos (2004, p. 7-8). Consideramos o pós-modernismo como uma denominação aplicada às mudanças ocorridas nas ciências, nas artes e nas sociedades desde a década de 1950, quando por convenção se encerra o modernismo e tomando consistência com o movimento da Arte Pop nos anos 1960.

Compreendi que era importante fazer uma análise de imagens que pudessem tecer noções sobre a cultura e a arte na contemporaneidade, no contexto histórico em que foram produzidas, procurando não só significados, mas entender a abrangência dos termos.

Houve um consenso de que a cultura é um conceito amplo determinado pelas

do, em redor dele não há uma linha que o fecha, mas um pontilhado permitindo abertura ao diálogo. No centro, está o ensino de arte, plataforma na qual acontecem as práticas pedagógicas não lineares podendo o professor se utilizar dos conceitos (narrativas, visualidades, produção artística e discurso visual) e das ações (problematizar, interpretar, analisar, criar, construir, contextualizar), conforme seu planejamento. 
relações sociais e envolve a necessidade de deixar registrado como memória costumes, identidades, etc. A cultura então, trata da arte, por meio das manifestações expressivas, produção artística, entre outras possibilidades. Intenso foram os comentários sobre o que poderia ser considerado arte ou não, ficando acordado a exibição de mais imagens de obras de artistas com produção após 1950, de forma a analisar a arte pós-moderna ou contemporânea.

Aliando o que vinha sendo discutido, na segunda aula fomos todos visitar a exposição do artista plástico Cláudio Tozzi, na Galeria Ana das Carrancas, do SESC Petrolina (vide Fig.2). A mostra se intitulava "Canteiro de Obras" e tinha boa parte dos trabalhos dentro da tendência contemporânea de criação: a busca por uma poética que define o trabalho do artista em períodos de inspiração no uso de materiais e métodos criativos.

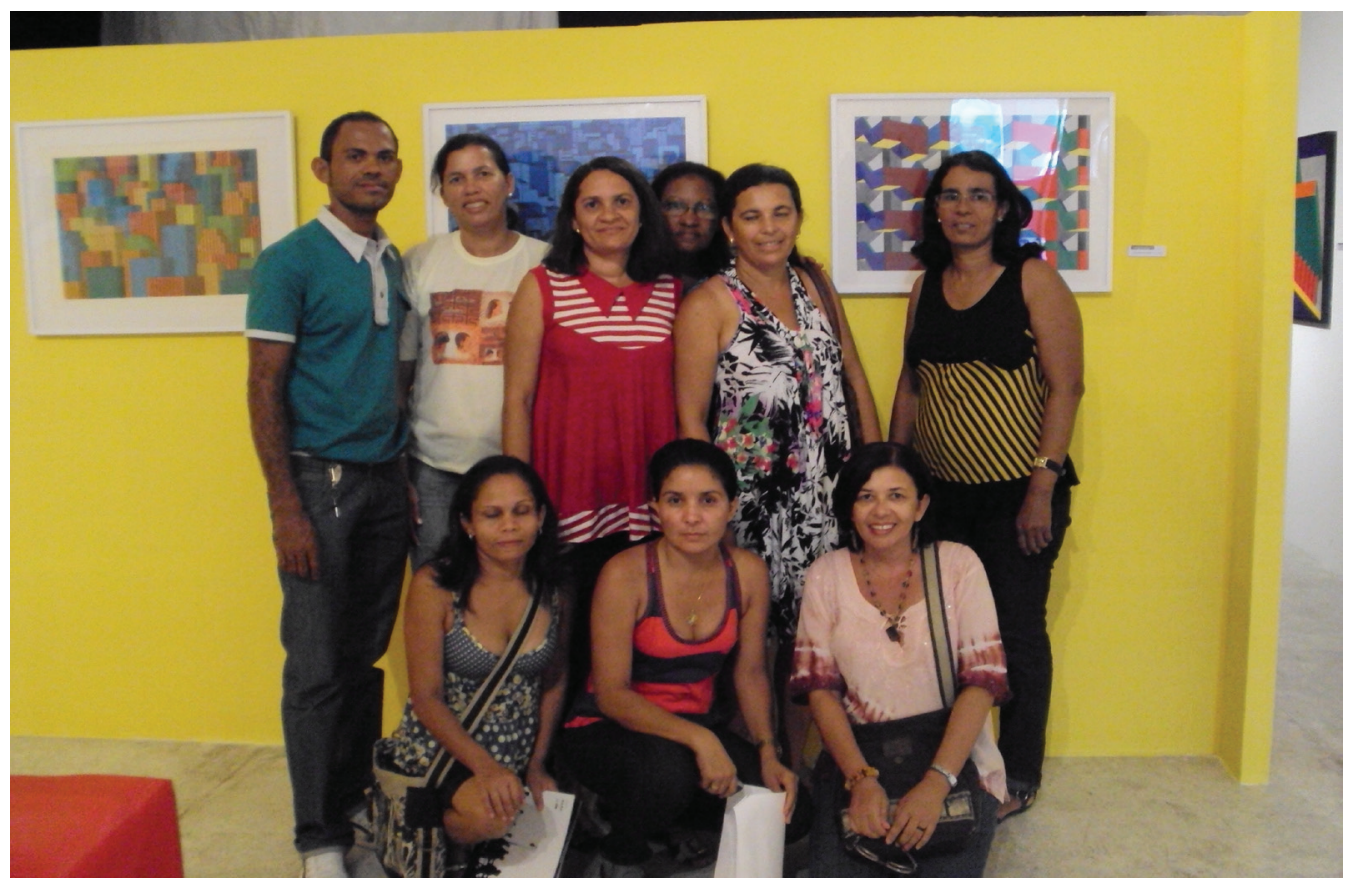

Fig.2: Turma na mostra Canteiro de Obras, de Cláudio Tozzi, Galeria SESC Ana das Carrancas, 2011.

Neste momento, diversos diálogos surgiram sobre as características das obras, em pinturas e instalações que demonstravam fases de criação. Percebi que muitos dos professores nunca haviam visitado uma mostra expositiva de trabalhos artísticos e procurei retirá-los do mero deslumbramento para um posicionamento mais crítico perante o que era visto, inserindo perguntas que analisavam o período, e os elementos visuais que as obras revelavam.

Nas aulas seguintes, durante os seminários, vimos e revimos conceitos em política 
públicas culturais, analisando os editais para a área de cultura e as leis de incentivo à cultura no Brasil e o papel desta políticas como ações de transformação e construção da sociedade. Percebemos a influência das políticas públicas culturais nas produções artístico/culturais e na consolidação de trabalhos no mercado de Arte.

Ao garantir a liberdade e a diversidade cultural, expliquei que as políticas públicas culturais funcionam como elementos dinamizadores do mercado de Arte, veia de divulgação, formação de público e de desenvolvimento de espaços para artistas das mais variadas vertentes criativas.

$\mathrm{Na}$ continuidade das discussões com os professores/alunos, questionamos o que rege a economia da cultura, na qual o entretenimento e as diversões são alguns dos principais efeitos da distribuição dos trabalhos artístico/culturais às massas, promovendo geração de emprego e renda em sua multiplicidade de versões, releituras, adaptações e renovações.

Alguns professores/alunos atestaram que em sua experiência pedagógica estas definições sofreram pré-conceitos promovidos pelas visões difundidas massivamente pelos cursos de graduação e formações continuadas que realizaram, concluindo em seus discursos que foram influenciados também pela visão da elite econômico/cultural no que é considerado como "tradição" em Cultura e Arte.

Nos debates, a maioria concordou na noção de que a Cultura agiria então como indicador e diferenciador da identidade dos indivíduos que a produzem e consomem em um movimento contínuo de construção, desconstrução, reconstrução do que é considerado como Cultura e, por conseguinte, como Arte.

A importância do registro da produção artístico/cultural, da memória percebida como parte indispensável da identidade social e a questão que envolve a preservação do patrimônio cultural (material e imaterial), fez com que os professores/alunos trouxessem à tona o debate acerca das aulas de Arte envolverem nas instituições educacionais conteúdos que abordem a educação patrimonial.

Dei exemplos de aulas de Arte que trabalham por meio da concepção MITEA, da educação infantil ao ensino médio, solicitando uma busca de respostas às problematizações que lançava e descrevia na lousa.

Dialogando criticamente conceitos, temas e questões relevantes, os processos didáticos na disciplina mediados pela MITEA, possibilitaram a visualização da Cultura e da Arte como vetores de desenvolvimento e como fatores de integração e coesão da sociedade.

\section{Por uma formação do artista/professor/pesquisador}

De acordo com minha experiência como docente na universidade, entendo a formação do professor em arte, especificamente na licenciatura em Artes Visuais, como 
fruto de vieses distintos que se intercomunicam na construção da identidade docente: a formação artística, a formação pedagógica e a formação em pesquisa/científica.

Considero que é necessário a experiência em práticas artísticas ao professor de Artes Visuais, como ferramenta didática ao exercício de seu trabalho e execução/explicação do uso de materiais e técnicas ao aluno. Também que este exercício esteja fundamentado em teorias e fundamentos que reflexionem sua didática, desenvolvida ao longo das disciplinas e dialogada nas práticas de ensino/estágios.

Para isso, dispus com o grupo de professores/alunos a realização de uma performance grupal, que relacionasse as discussões teóricas e leituras de imagens e vídeos com uma prática artística. Solicitei que trouxessem materiais e a ideia pronta na última aula, que deveria tratar também da avaliação da disciplina.

O resultado (vide Fig. 3) foi uma performance sobre a música "Comida", composição de Arnaldo Antunes, Marcelo Fromer e Sérgio Britto, na qual, de um lado, um deles enunciava a parte em que se questiona ("Você tem sede de que? Você tem fome de que?") e o restante afirmava com trechos da música a necessidade da arte na vida.

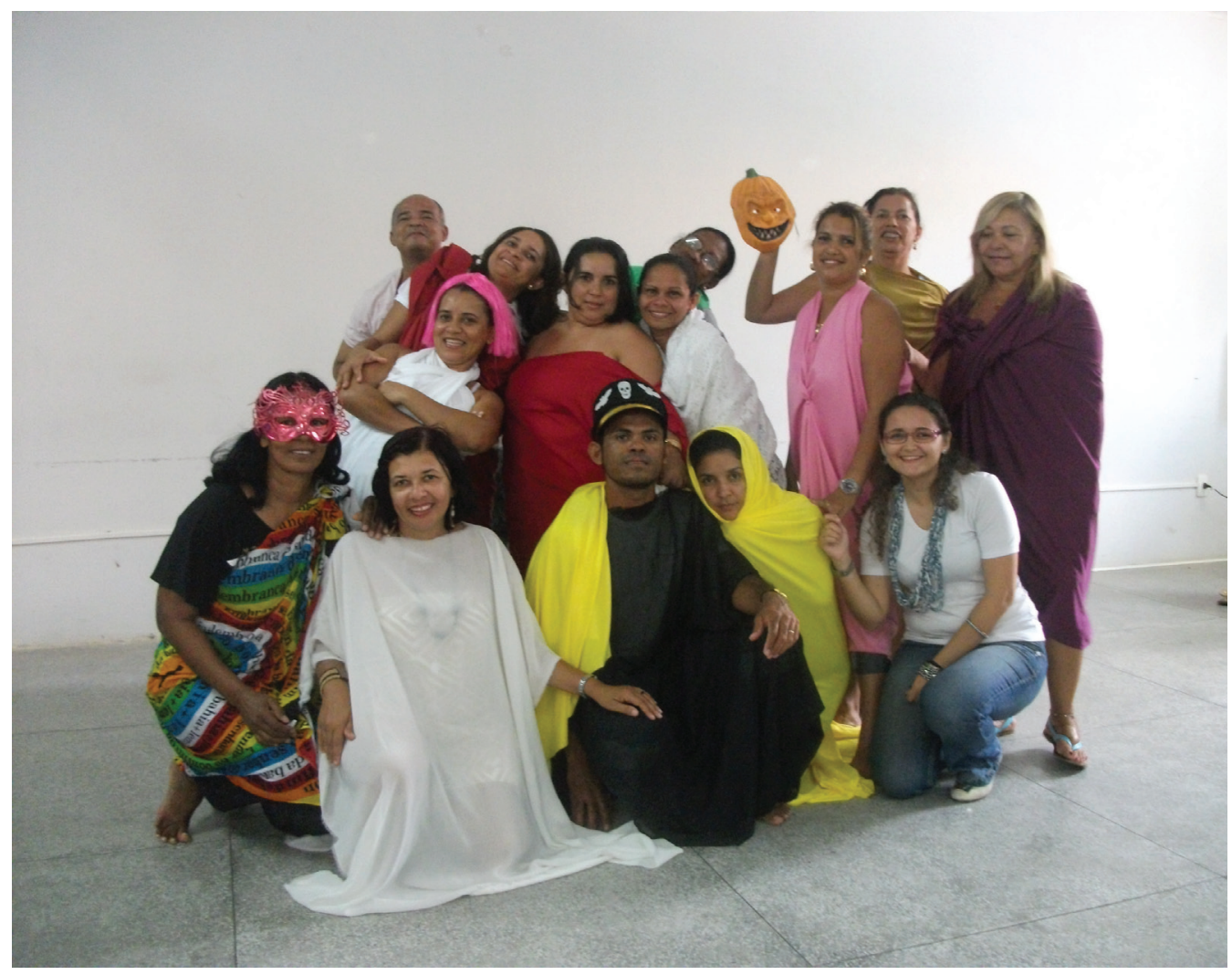

Fig. 3: Com toda a turma, no último dia de encontro, após performance grupal na avaliação da disciplina Cultura e Arte Contemporânea, 2011. 
Após a atividade de performance, compreendo como essencial o relacionar com as práticas artístico/pedagógicas, em que se produz, ensina e aprende, das concepções teóricas trabalhadas em uma disciplina na universidade. Assim, percebe-se que o viés do pesquisador é estimulado, na comunicação das conceituações e práticas pedagógicas, produtos artísticos, entre outras questões a serem divulgadas para além dos muros da universidade e das escolas.

Refletindo acerca da formação do professor de Artes Visuais no Brasil, Richter (apud OLIVEIRA; HERNANDEZ, 2005, p.54) aponta que a formação do professor deverá ser múltipla, sendo que somente por seu conhecimento e domínio das diferentes teorias em ensino das Artes Visuais estará apto a desempenhar coerentemente seu papel de agente cultural e pedagógico.

No curso de Licenciatura em Artes Visuais da UNEB, a formação do professor que já está na sala de aula lecionando a disciplina Artes, seja no Ensino Fundamental, Educação de Jovens e Adultos (EJA) ou no Ensino Médio em escolas públicas municipais e estaduais, se constitui como caminho indispensável a construção desse professor/aluno.

Para muitos deles, ser licenciado em Artes Visuais é um “abrir de portas” pedagógico, oportunidade de formação incentivada pelos incentivos de novas políticas públicas educacionais, afirmada em depoimento em e-mail que recebi após o término das atividades por uma das professoras/alunas muito participativa durante as aulas presenciais e também em debates virtuais, como pode ser visto em seu relato:

Agora estou no caminho de alcançar meu objetivo, me tornar uma professora licenciada em Artes...cada novo modulo tenho mais certeza que estou no caminho certo e pretendo ir longe, nesta área do conhecimento. A Arte é algo que me fascina e percebo isso também na maioria dos alunos. (GONÇALVES, 2011)

A formação na área específica de atuação traz uma ampliação pedagógica necessária ao professor/aluno em conceitos e fundamentos que envolvem Cultura e Arte, compreensão e construção de processos criativos em produções artísticas e investigação de temas, conteúdos e processos didáticos em pesquisas.

O perfil do egresso em cursos de licenciatura em Artes Visuais, atualmente, está pendendo cada vez mais para as necessidades do mercado de trabalho, do profissional que é também MIT na atuação: o artista/professor/pesquisador, que de acordo com Irwin (2008) é compreendido como profissional que realiza um processo a/r/tográfico, ou seja, mediador de diversas potencialidades da produção poética, do ensino e da pesquisa em Arte.

Estes profissionais vêm adquirido espaços mais amplos, em que seu campo de trabalho é situado, seja em instituições de ensino formal (escolas e universidades), ensino não-formal (ONG's, escolas de artes, entidades associativas, hospitais, etc.), seja em assessoria educacional, em projetos e editais culturais. 
No trabalho de Almeida (2010), as ações que o professor de artes opta por trabalhar nas aulas de artes visuais são analisadas por meio da ênfase com que dão a determinados aspectos. São os seguintes: imaginação, criatividade, forma, contexto, representação mimética, história da arte, leitura da obra de arte e técnicas do aprendizado artístico.

Como Almeida, entendo que os desvios didáticos que a disciplina Arte atravessa no currículo escolar e na prática docente partem da ênfase com que os profissionais que lecionam a disciplina dão a determinados pontos de visão, advindos de formação não adequada em teorias e práticas artísticas, o que é percebido e diagnosticado, infelizmente, em grande maioria das instituições educacionais nordestinas e boa parte das brasileiras.

Enfim, a experiência de ensino na UNEB com professores/alunos me fez compreender que a valorização da disciplina Arte no currículo escolar brasileiro depende diretamente da maneira com a qual é dirigida e visualizada a formação do professor que leciona a disciplina. É fundamental que ele tenha consciência da relevância da área de Arte como conhecimento, pois:

A arte não é apenas básica, mas fundamental na educação de um país que se desenvolve. Arte não é enfeite. Arte é cognição, é profissão, é uma forma diferente da palavra para interpretar o mundo, a realidade, o imaginário, e é conteúdo. Como conteúdo, a arte representa o melhor trabalho do ser humano (BARBOSA, 2009, p.4).

Em suma, a formação do artista/professor/pesquisador em uma licenciatura em Artes Visuais, que atravessa entendimentos múltiplos em Cultura e Arte, é uma referência na formação de indivíduos, que não só respeitam a diversidade artístico/cultural, mas dialeticamente constroem sentidos e significados que desdobram, transformam e revolucionam saberes ao construir e constituir narrativas reflexivas.

\section{Referências bibliográficas}

ALMEIDA, Célia Maria de Castro. Ser Artista, ser professor: razões e paixões do ofício. São Paulo: Ed; UNESP, 2010.

BARBOSA, Ana Mae. A imagem no ensino da arte: anos 1980 e novos tempos. $7^{\mathrm{a}}$ ed. São Paulo: Perspectiva, 2009.

FREIRE, Paulo. Pedagogia do Oprimido. Rio de Janeiro: Paz e Terra, 2005.

GONÇALVES, Rubenilde da Silva. Re: Como me tornei professora de Artes. [mensagem pessoal]. Mensagem recebida por flapedrosa@gmail.com. Acesso em: 07 de março 
de 2011.

IRWIN, Rita. A/r/tografia: uma mestiçagem metonímica In: BARBOSA, Ana Mae; AMARAL, Lilian. (org.). Interterritorialidade: mídias, contexto e educação. São Paulo: Editora Senac São Paulo ; Edições SESC SP , 2008.

RICHTER, Ivone Mendes. A formação do professor de artes visuais em uma perspectiva internacional: implicações para o ensino de arte no Brasil. In: OLIVEIRA, Marilda Oliveira de; HERNANDEZ, Fernando. (Orgs.). A formação do professor e o ensino das artes visuais. Santa Maria: Ed. UFSM, 2005.

SANTOS, Jair Ferreira dos. O que é Pós-moderno. São Paulo: Brasiliense, 2004.

VASCONCELLOS, Celso dos Santos. A construção do conhecimento em sala de aula. São Paulo: Libertad, 2009.

VASCONCELOS, Flávia Maria de Brito Pedrosa. Proposta Curricular de Juazeiro Direito de Aprender: Artes. $1^{\circ}$ ao $9^{\circ}$ ano do ensino fundamental. Juazeiro - BA: Gráfica Obelisco, 2011.

. Narrativas no ensino de Artes Vi-

suais em Juazeiro/BA e Petrolina/PE. 2011b. 151f. Dissertação (Mestrado em Artes Visuais) - Programa de Pós-graduação em Artes Visuais, Universidade Federal da Paraíba e Universidade Federal de Pernambuco, João Pessoa, PB, 2011a. 